\title{
Dysmorphic Erythrocyte Count
}

National Cancer Institute

\section{Source}

National Cancer Institute. Dysmorphic Erythrocyte Count. NCI Thesaurus. Code C135441.

The determination of the amount of dysmorphic erythrocytes present in a sample. 